\title{
O PRINCÍPIO DA PROTEÇÃO INTEGRAL DA CRIANÇA E DO ADOLESCENTE DIANTE DA SUSPENSÃO OU DESTITUIÇÃO DO PODER FAMILIAR
}

\section{THE PRINCIPLE OF THE COMPREHENSIVE PROTECTION OF CHILDREN AND ADOLESCENTS BEFORE THE SUSPENSION OR DISPOSITION OF THE FAMILY POWER}

\begin{abstract}
Mirian Alves de Oliveira
Acadêmica do Curso de Direito na Faculdade Presidente Antônio Carlos de Teófilo Otoni.

E-mail: miryanoliveira09@hotmail.com
\end{abstract}

Fernanda da Silva Freitas

Advogada e Professora de Direito na Faculdade Presidente Antônio Carlos de Teófilo Otoni.

Especialista em Direito Público e em Docência no Ensino Superior.

E-mail:ferna-freitas@hotmail.com

Márcio Júnio Batista Pereira

Advogado e Professor na Faculdade Presidente Antônio Carlos de Teófilo Otoni. Especialista em Direito do Trabalho e Direito Previdenciário.

E-mail: marciojuniotoadv@hotmail.com

\section{Resumo}

O princípio da proteção integral da criança e do adolescente ou princípio do melhor interesse da criança e do adolescente está fundamentado no artigo 227 da Constituição Federal de 1988, que estabelece ser dever da família, da sociedade e do Estado garantirem tanto à criança como ao adolescente, com prioridade absoluta, os direitos fundamentais como a vida, a saúde, a alimentação, a educação, dignidade e respeito, além de colocar a criança e o adolescente a salvo de qualquer situação de negligência, discriminação, exploração, violência, crueldade e opressão. Através do poder familiar são conferidos aos pais deveres e direitos sobre os filhos menores no que tange à criação, educação, exigência da prestação de respeito e obediência no exercício da guarda, sendo esta compartilhada ou unilateral conforme previsão no Código Civil de 2002. Autorização ou impedimento do casamento dos filhos, autorização ou impedimento para viajarem ao exterior, dentre outros, também são deveres dos pais no exercício do poder familiar. Assim o presente trabalho se propõe a estudar o poder familiar e suas hipóteses de suspensão e destituição. $O$ trabalho foi construído através de metodologia de pesquisa bibliográfica qualitativa no tocante ao problema identificado No que refere-se a abordagem dos objetivos propostos foi utilizada a metodologia descritiva. Verifica-se que o poder familiar é a concessão e o exercício do poder que os pais têm sobre os filhos, sobre os seus bens, direitos e obrigações, ainda que temporariamente. Ressalta-se que os pais precisam estar atentos aos atributos a eles confiados, para que o exercício do poder 
familiar seja mantido, sem perder de vista a garantia do melhor interesse da criança e do adolescente.

Palavras - Chave: Poder Familiar - Melhor Interesse da Criança e do Adolescente - Suspensão - Destituição.

\section{Abstract}

The principle of the integral protection of the child and the adolescent or principle of the best interest of the child and the adolescent is based on the article 227 of the federal constitution of 1988, being duty of the family, of the society and of the State to guarantee both the child and the adolescent with fundamental rights such as life, health, food, education, dignity and respect and other fundamental rights, and to safeguard children against neglect, discrimination, exploitation, violence, oppression. Family power is an institute of family law where parents are given the duties and rights over minor children in matters of upbringing, education, the requirement to provide respect and obedience, in the exercise of the guard being shared or unilateral according to in the civil code of 2002, in the authorization or impediment of the marriage of the children, in the authorization or impediment to travel abroad and other rights and duties. Therefore, the present work is oriented toward the study of family power and its hypotheses of suspension and dismissal. The work was constructed through qualitative bibliographic research methodology in relation to the identified problem, and in the approach of the proposed objectives the descriptive methodology was used. The family power is thegranting of the exercise that the parents have before their children and their assets, rights and obligations, although temporarily they need to be attentive to the attributes entrusted to them, so that the exercise of family power is maintained, without losing in order to guarantee the best interests of the child and the adolescent.

Keywords: Family Power - Best Interests of the Child and the Adolescent Suspension - Destitution.

\section{Introdução}

O trabalho em questão tem como linha de pesquisa o Direito Civil e de forma mais específica o Direito de Família que é o ramo do direito que especifica as regras para uma convivência harmoniosa em família. As referidas regras são de observância obrigatória pelos membros de uma família já que visam a sua proteção, organização, dentre outros aspectos que se referirem à convivência familiar.

O poder familiar é um instituto do Direito de Família através do qual é conferido aos pais deveres e direitos sobre os filhos menores no que tange à sua criação, educação e exigência da prestação de respeito e obediência, no exercício da guarda, sendo esta compartilhada ou unilateral conforme previsão no Código Civil de 2002. A autorização ou impedimento do casamento dos filhos, autorização ou 
impedimento para viajarem ao exterior, dentre outros, também constituem deveres dos pais no exercício do poder familiar.

O princípio da proteção integral da criança e do adolescente ou princípio do melhor interesse da criança e do adolescente está fundamentado no artigo 227 da Constituição Federal de 1988, sendo dever da família, da sociedade e do Estado garantir tanto à criança como ao adolescente, com prioridade absoluta, os direitos fundamentais como a vida, a saúde, a alimentação, a educação, dignidade e respeito, dentre outros direitos fundamentais. Além disso,pela força dos supramencionados princípios a criança e o adolescente devem viver a salvo de qualquer situação de negligência, discriminação, exploração, violência, crueldade e opressão. Em suma, o presente trabalho se propõe ao estudo do poder familiar.

Considerando-se que a Constituição Federal de 1988 garantiu e impôs aos pais direitos e dever sobre os filhos menores é primeiramente dos pais o dever de proteção desses filhos. Verifica-se que por diversas vezes muitos pais não têm cumprido tais deveres, mas, inobstante isso, exigem dos filhos menores o respeito e a obediência também decorrentes do princípio da proteção integral. Diante dessa situação, foi identificado o seguinte problema: considerando o princípio da proteção integral da criança e do adolescente, em quais circunstâncias é cabível a suspensão ou destituição do poder familiar?

O Estatuto da Criança e do Adolescente, lei 8.069/90, ratificou os deveres e direitos dos pais sobre os filhos menores, consubstanciados na exigência de respeito e obediência, mas principalmente na proteção dos menores e na garantia dos seus direitos fundamentais.

O trabalho foi construído mediante metodologia de pesquisa bibliográfica qualitativa no tocante ao problema identificado. Na abordagem dos objetivos propostos foi utilizada a metodologia descritiva, por meio de utilização de doutrinas clássicas e contemporâneas da área do Direito Civil, mais especificamente do ramo do Direito de Família, bem como a legislação brasileira aplicada ao assunto como o Código Civil de 2002, Constituição Federal de 1988 e Estatuto da Criança e do Adolescente, dentre outras. As fontes de informações utilizadas foram livros da área jurídica e artigos científicos, publicados em formato físico e virtual e com indexação em bases de dados como scielo, e demais periódicos publicados entre 2014 e 2018.

\section{Da evolução do poder familiar}


Conforme explica a doutrina civilista existiu um modelo muito diferente de família em relação ao modelo dos dias atuais, sendo que na família romana vigorava o princípio do pater famílias, onde o pai exercia seu poder de forma indiscriminada sobre a família. Nenhum ato praticado pelo pai podia ser contestados, pois a ele estavam subordinados não apenas os filhos, mas os netos, a esposa, os irmãos, os escravos e até os clientes.

O poder concedido ao pai era tão absoluto que ele podia sacrificar o próprio filho em benefício do grupo familiar, vender o filho para resolver uma crise financeira ou entregar o filho como uma espécie de indenização à vitima que sofreu um dano causado pelo filho.Desta forma o filho prestaria os serviços que a vítima precisasse, sendo que em casos de venda, o pai poderia ficar por até cinco anos sem possuir sobre si o exercício do pater famílias ou pátrio poder.Outro poder concedido ao pai no modelo romano era a faculdade de ficar com o filho recém-nascido ou abandonálo caso esse filho fosse gerado com algum tipo de deficiência (MADALENO, 2016).

A doutrina preceitua que o cristianismo teve uma importante colaboração na história para que houvesse a extinção do pater famílias, já que Roma passou a adotar o cristianismo como sua religião oficial, e houve um conflito das leis com o cristianismo. Em um dado momento não foi mais possível manter essa autoridade absoluta que o pai exercia sobre a sua família e a partir de então passou a ser proibida tanto a venda dos filhos, quanto a entrega dos mesmos com o objetivo de compensação ou ainda a morte.

No Código Civil de 1916 foi atribuído ao marido o pátria potestas ou pátrio poder, dessa maneira, o pai exercia de forma quase absoluta o seu poder, porém em casos excepcionais o pátrio poder era concedido à mãe, como em casos de impedimento ou ausência do pai. Contudo se o pai e a mãe discordassem em alguma questão, predominaria a decisão do pai. Ressalta-se que a única forma de não prevalência dessa decisão seria em casos de abuso de autoridade, de acordo com o art. 160, I, segunda parte, do Código Civil de 1916 (LÔBO, 2011).

Em 1962 com a lei 4.121 foi promulgado o Estatuto da Mulher Casada, nele constava que o pátrio poder já não seria mais sucessivo, mas seria exercido de forma simultânea, ou seja, foi também conferida dada a mulher o exercício do pátrio poder e caso houvesse algum conflito entre homem e mulher, prevaleceria a decisão 
do pai, porém a mulher poderia recorrer ao Poder Judiciário para solucionar o conflito (LÔBO, 2011).

Ainda sob a influência do cristianismo, com a constituição de 1988 houve o ajuste referente ao exercício do pátrio poder, sendo este então exercido de forma igual, ou seja, pai e mãe teriam a igualdade de poder sobre os filhos, conforme o art. 226, parágrafo $5^{0}$.

Assim afirma Madaleno (2016, p. 1026):

Com a influência do cristianismo o poder familiar assumiu características de direito protetivo, tornando-se uma imposição de ordem pública, no sentido de os pais zelarem pela formação integral dos filhos, com o alcance determinado pelo artigo 227 da Constituição Federal brasileira, merecendo o menor especial destaque, alvo de absoluta prioridade, sendo assegurado à criança e ao adolescente e agora também ao jovem, em razão da Emenda Constitucional n. 65/2010 e do Estatuto da Juventude (Lei n. 12.852/2013), o direito à vida, à saúde, à alimentação, à educação, ao lazer, à profissionalização, à cultura, à dignidade, ao respeito, à liberdade e à convivência familiar e comunitária, deixando-o a salvo de toda forma de negligência, discriminação, exploração, violência, crueldade e opressão.

No mesmo sentido, Lôbo (2011, p. 296): "a mudança foi muito mais intensa, na medida em que o interesse dos pais está condicionado ao interesse do filho, ou melhor, ao interesse de sua realização como pessoa em desenvolvimento".

Entretanto somente com o código de 2002 houve a alteração da expressão Pátrio Poder para Poder familiar. Para Gonçalves(2017, p. 422):

O poder familiar é uma atribuição conferida aos pais quanto a direitos e deveres referente à pessoa e aos bens dos filhos menores. Entende-se que esses deveres e direitos são temporários, pois se tratam dos filhos menores ou até a emancipação desses filhos.

Existe uma grande crítica por parte da doutrina em relação à expressão poder familiar, já que esta entende não ser o nome mais adequado diante de tantas mudanças ocorridas no modelo de família com a Constituição Federal de 1988 e o Código Civil de 2002. Isso porque a expressão "Poder Familiar" denota poder, causando a impressão de que ainda exista um poder agora não só do pai em relação aos filhos, mas da família em relação a esses (BRASIL, 2002).

O entendimento da doutrina é que a denominação mais adequada para esse instituto seria a "autoridade parental", como é intitulado em algumas legislações estrangeiras. Segundo os defensores dessa corrente "autoridade parental" traduz 
melhor este instituto já que a palavra poder ainda remete à coação física ou psíquica que lhe é inerente.

Importante é salientar que o instituto do poder familiar se caracteriza pela proteção concedida ao menor, atendendo ao princípio da paternidade responsável que está elencado no artigo 226 , parágrafo $7^{\circ}$ da constituição federal, conforme preceitua Gonçalves (2017, p. 466):

Modernamente, graças à influência do Cristianismo, o poder familiar constitui um conjunto de deveres, transformando-se em instituto de caráter eminentemente protetivo, que transcende a órbita do direito privado para ingressar no âmbito do direito público. Interessa ao Estado, com efeito, assegurar a proteção das gerações novas, que representam o futuro da sociedade e da nação. Desse modo, o poder familiar nada mais é do que um munus público, imposto pelo Estado aos pais, a fim de que zelem pelo futuro de seus filhos.

Sendo assim, o poder familiar deve ser observado prioritariamente para 0 interesse e harmonia da família e dos filhos. $O$ instituto do poder familiar possui características a ele inerentes, como a irrenunciabilidade, por meio da qual o pai ou a mãe não podem dizer que não querem exercer o poder familiar estando o filho sob a sua autoridade; o poder familiar é também indelegável, ou seja, não pode ser transferido a outra pessoa, salvo na condição do art. 166 do Estatuo da Criança e do Adolescente, quando houver o pedido de colocação do menor em uma família substituta dentro dos preceitos da lei, como é o caso da adoção, onde o adotante exercerá então o poder familiar sobre o menor; o poder familiar é imprescritível, sendo que o genitor ainda que não o exerça, somente poderá perdê-lo conforme previsão legal e é incompatível com a tutela, sendo que o menor não poderá ter um tutor se os pais não foram suspensos ou destituídos do exercício do poder familiar (BRASIL, 1990).

Importante ressaltar que o poder familiar decorre da filiação, sendo em regra o exercício do poder familiar inerente aos pais sobre seus filhos.De acordo com Gonçalves(2017, p. 423):

o exercício do poder familiar independe sobre da condição da filiação, desde que ocorra o reconhecimento dos mesmos por seus genitores, ou seja, não há que se contestar se o filho é biológico ou adotado, havendo o reconhecimento pelos genitores, haverá o exercício do poder familiar.

Conforme o art. 1.632 do Código Civil, a condição também do casal não altera o exercício do poder familiar. Assim, estando o casal separado judicialmente, 
divorciado ou havendo dissolução da união estável estes deverão exercer o poder familiar sobre os filhos menores (BRASIL, 2002).

No que diz respeito ao exercício do poder familiar em relação ao filho tido fora do casamento, é claro o art. 1633 do Código Civil de 2002. Caso o pai não reconheça tal filho, será exclusividade da mãe o exercício do poder familiar e em casos em que a mãe for incapaz, caberá ao juiz a nomeação de um tutor à criança, até que essa atinja a maioridade ou seja emancipada por sentença judicial.

\title{
2.1 Atributos atuais do poder familiar
}

O art. 1634 do Código Civil de 2002, nos incisos I ao IX relacionam quais são os atributos do poder familiar, ou seja, em que consiste o exercício do poder familiar.Sobre o conceito dos atributos do poder familiar afirma Lôbo $(2011$, p. 303):

\begin{abstract}
Os pais não exercem poderes e competências privados, mas direitos vinculados a deveres e cumprem deveres cujos titulares são os filhos. Por exemplo, os pais têm o direito de dirigir a educação e a criação dos filhos e, ao mesmo tempo, o dever de assegurá-las. Enquanto estreitamente funcionalizado ao interesse do menor e à formação de sua personalidade, $\mathrm{O}$ exercício do poder familiar evolui no curso da formação da personalidade. À medida que o menor desenvolve sua própria capacidade de escolha, o poder familiar reduz-se proporcionalmente, findando quando atinge seu limite temporal.
\end{abstract}

Sendo assim, entende-se que os atributos do poder familiar estão relacionados à própria definição do que seja o exercício do poder familiar.Conforme reza o artigo 1.634 do Código Civil são atributos do poder familiar a educação, a guarda compartilhada conforme previsão legal, a concessão ou impedimento para que os filhos se casem, bem como, viajem ao exterior ou mudem sua residência de forma permanente para outro município, a nomeação de tutor por testamento ou documento autêntico em caso de impossibilidade do exercício pelos pais, a representação judicial ou extrajudicial até os dezesseis anos e a assistência quando tiverem idade acima dos dezesseis anos até os dezoito anos, reclamá-los de quem os detenha de forma ilegal e exigir a prestação de respeito, obediência e os serviços próprios de sua idade e condição (BRASIL, 2002).

São claros os atributos elencados no artigo 1.634 do Código Civil de 2002, porém é importante observar que o atributo educação engloba uma série de outras questões. Senão vejamos. 
Para Lôbo (2011, p. 297):

a educação não se resume em educação escolar, mas inclui o ensinamento da moral, de princípios religiosos, políticos e cívicos que se encontram dentro da família, tendo em vista que o filho ainda está em formação, cabendo aos pais adotar medidas que ensinem aos filhos a conviverem em sociedade, já que a formação moral abre e eleva a consciência para valores.

Nas palavras de Madaleno(2016, p. 1026):

- exercício de atributos do poder familiar decorre do artigo 229 da Constituição Federal, que impõe aos pais os deveres de criação e educação, como também do artigo 21 do Estatuto da Criança e do Adolescente ao instituir aos pais o dever de guardar, sustentar e educar os filhos menores.

Ainda conforme posicionamento de Madaleno (2017, p. 1027):

o dever de educar engloba a preparação do filho para a sua independência pessoal, de forma que os pais possam qualificar os filhos para exercerem a vida profissional, através de conhecimentos práticos, teóricos, formais ou informais afim de contribuírem para uma boa formação espiritual, física e mental, conforme previsão do artigo $3^{\text {o }}$ do Estatuto da Criança e do Adolescente.

Entende-se que todos os atributos do poder familiar são de extrema importância na preparação do menor para, além de saber viver em sociedade, obter a sua dignidade que é inerente a toda a pessoa humana.

Conforme artigo 1635 do Código Civil são causas de extinção do poder familiar a morte do filho, dos pais, a emancipação, a maioridade, a adoção e conforme decisão judicial, nos termos do artigo 1638 do Código Civil de 2002.

\section{Princípio da Proteção da Criança e do Adolescente}

O princípio da proteção da criança e do adolescente, também classificado pela doutrina como princípio do melhor interesse da criança e do adolescente, está fundamentado no artigo 227 da Constituição Federal de 1988 ao descrever:

Art. 227. É dever da família, da sociedade e do Estado assegurar à criança, ao adolescente e ao jovem, com absoluta prioridade, o direito à vida, à saúde, à alimentação, à educação, ao lazer, à profissionalização, à cultura, à dignidade, ao respeito, à liberdade e à convivência familiar e comunitária, 
além de colocá-los a salvo de toda forma de negligência, discriminação, exploração, violência, crueldade e opressão.

Conforme prevê a Constituição Federal, deve ser dispensada à criança, adolescente ou ao jovem toda a prioridade necessária para que seus direitos fundamentais sejam garantidos sendo que a garantia desses direitos é dever da sociedade, da família, e do Estado.

Para Lôbo (2011, p. 301): "a Convenção Internacional dos Direitos da Criança, devidamente reconhecida em 1990 no Brasil, todos os atos relacionados aos menores devem ter como prioridade o maior interesse da criança." Aos menores deve ser garantida a amplitude da proteção, com o emprego de esforços em escala mundial com o fim de fortalecer juridicamente a situação dos menores, eliminando qualquer tipo de diferença entre filhos legítimos de ilegítimos. Deu-se aos pais a tarefa conjunta de cuidar do desenvolvimento e da educação dos menores.

De acordo com Dias (2016) no fato de a criança e do adolescente terem uma maior vulnerabilidade e fragilidade justifica o tratamento especial a eles dispensado. Devido a isso, a eles é garantida, toda a prioridade necessária, para a concretização de seus direitos fundamentais. O princípio da proteção integral, ou melhor, interesse da criança e do adolescente também é identificado no Estatuto da Criança e do Adolescente, lei 8.069/90 nos artigos $4^{\mathrm{a}}$ e $6^{\circ}$.

Conforme Lôbo (2011, p. 305), o pátrio poder vigia em função única e exclusiva do pai, que nos casos de separação, não se considerava o que seria melhor para a criança, já que esta era irrelevante, sempre ficava em segundo plano, com isso, a criança ou adolescente era um mero objeto em casos de intervenção jurídica, onde sempre era considerado em primeiro plano o interesse do pai. Porém, com poder familiar a criança e o adolescente tornaram-se sujeitos de direitos, consideradas como pessoas peculiares, em desenvolvimento, o que proporcionou uma grande evolução.

A evolução no novo modelo de família representa verdadeiro avanço jurídico e social com a abolição do pátrio poder do Código Civil de 1916, onde o pai era a prioridade nas relações de família, nas relações jurídicas e na sociedade, o que não ocorre diante do poder familiar, instituído na Constituição/1988, Estatuto da Criança e do Adolescente, Convenção Internacional de 1990 e no Código Civil de 2002.

Assim afirma Lôbo (2011, p. 77): 
O princípio do melhor interesse ilumina a investigação das paternidades e filiações socioafetivas. A criança é o protagonista principal, na atualidade. No passado recente, em havendo conflito, a aplicação do direito era mobilizada para os interesses dos pais, sendo a criança mero objeto da decisão. O juiz deve sempre, na colisão da verdade biológica com a verdade socioafetiva, apurar qual delas contempla o melhor interesse dos filhos, em cada caso, tendo em conta a pessoa em formação.

Em concordância, Madaleno (2016, p. 168):

Dessa forma seria inconcebível admitir pudesse qualquer decisão envolvendo os interesses de crianças e adolescentes fazer tábula rasa do princípio dos seus melhores interesses, reputando-se inconstitucional a aplicação circunstancial de qualquer norma ou decisão judicial que desrespeite os interesses prevalentes da criança e do adolescente recepcionados pela Carta Federal.

Considerando que o melhor interesse da criança e do adolescente deve ser o centro das decisões judiciais, identifica-se que o melhor interesse da criança e do adolescente é de tamanha importância que deve prevalecer em todas as áreas, sejam sociais, nas relações familiares e profissionais. E não poderia ser diferente nas decisões judiciais.Não cabe, portanto ao Estado se sobrepor a esse princípio, de tamanha importância para o desenvolvimento da criança e do adolescente, uma vez que em diversas situações o adulto de amanhã poderá vir a serreflexo de uma postura do Estado nos dias de hoje.

\section{Suspensão e destituição como consequências jurídicas da infração no exercício do poder familiar}

A suspensão do poder familiar, de acordo com a doutrina, é uma forma de garantir o melhor interesse da criança ou do adolescente, não podendo ser enxergada pela sociedade como uma forma de punição aos pais, pois a suspensão ocorrerá em casos menos graves. Defendem diversos doutrinadores que embora o Código Civil de 2002 em seu artigo 1.637 trate das situações em que ocorrerá a suspensão do poder familiar, tais situações apresentam de forma genérica, ficando a critério do juiz adotar a suspensão ou medidas de restrição do poder familiar em situações diversas.

Reza o art. 1.637 e parágrafo único do citado artigo do Código Civil de 2002:

Art. 1.637. Se o pai, ou a mãe, abusar de sua autoridade, faltando aos deveres a eles inerentes ou arruinando os bens dos filhos, cabe ao juiz, 
requerendo algum parente, ou o Ministério Público, adotar a medida que the pareça reclamada pela segurança do menor e seus haveres, até suspendendo o poder familiar, quando convenha.

Parágrafo único. Suspende-se igualmente o exercício do poder familiar ao pai ou à mãe condenados por sentença irrecorrível, em virtude de crime cuja pena exceda a dois anos de prisão.

A suspensão pode ser temporária ou total, conforme Madaleno (2016, p.169):

a suspensão temporária perdurará até que se cessada a sua causa. O juiz ainda poderá impor aos pais condições individuais, sendo de obrigação do pai ou da mãe o devido cumprimento. A suspensão total ocorrerá de forma a abranger todos os atos inerentes ao poder familiar, desde o pai ou a mãe ser privado da administração do bens do menor, até a privação do convívio com o mesmo, não podendo o pai ou a mãe usufruir dos bens do menor.

De acordo com Lôbo (2011, p. 89): “a perda do poder familiar deverá ocorrer somente quando o ato praticado pelo genitor ou genitora for de tamanha importância ao ponto de por em risco permanente a segurança e a dignidade do filho."

Conforme assegura o artigo 1638 do Código Civil de 2002 ocorrerá a perda ou destituição do poder familiar nos seguintes casos:

Art. 1.638. Perderá por ato judicial o poder familiar o pai ou a mãe que: I castigar imoderadamente o filho; II - deixar o filho em abandono; III - praticar atos contrários à moral e aos bons costumes; IV - incidir, reiteradamente, nas faltas previstas no artigo antecedente. $\mathrm{V}$ - entregar de forma irregular $\mathrm{o}$ filho a terceiros para fins de adoção.

De acordo com Madaleno (2016, p. 170): “o castigo reiterado levará à destituição do poder familiar, considerando que ocorre um abuso de autoridade, violência à integridade física da criança ou adolescente, bem como a ofensa à sua dignidade."No que se refere a castigar imoderadamente o filho, a doutrina faz a ressalva de que o castigo não deve ocorrer nem de forma moderada, considerando a lei 13.010/2014, intitulada de Lei do Menino Bernardo, que prevê que o castigo físico não deve ser adotado de nenhuma forma, sendo que a educação aos filhos deve ocorrer por meio do diálogo e compreensão, sendo o castigo físico ainda que moderado um ilícito civil. Em relação a deixar o filho em abandono, a doutrina ensina que o abandono aqui se refere ao abandono moral, intelectual, material e por vezes até afetivo. Conforme Gonçalves (2017, p. 485):

o abandono priva o filho da convivência da família e da sociedade o que viola o artigo 227 da Constituição Federal, prejudicando a criança e o 
adolescente nas mais diversas áreas. A falta de assistência material coloca em perigo a sobrevivência e a saúde do filho, porém não representa a única forma de abandono, podendo este também se dar na modalidade moral e intelectual.

Quanto ao inciso III, do artigo 1638, do Código Civil de 2002, que impede a pratica de atos contrários à moral e aos bons costumes, de forma clara explica Gonçalves (2017, p. 487):

\begin{abstract}
O lar é uma escola onde se forma a personalidade dos filhos. Sendo eles facilmente influenciáveis, devem os pais manter uma postura digna e honrada, para que nela se amolde o caráter daqueles. A falta de pudor, a libertinagem, o sexo sem recato podem ter influência maléfica sobre o posicionamento futuro dos descendentes na sociedade, no tocante a tais questões, sendo muitas vezes a causa que leva as filhas menores a se entregarem à prostituição. Mas o dispositivo em tela tem uma amplitude maior, abrangendo o procedimento moral e social sob diversos aspectos. Assim, o alcoolismo, a vadiagem, a mendicância, o uso de substâncias entorpecentes, a prática da prostituição e muitas outras condutas antissociais se incluem na expressão "atos contrários à moral e aos bons costumes".
\end{abstract}

Entende-se que quaisquer práticas de imoralidade e maus costumes levam à destituição do poder familiar, cabendo aos pais ensinar princípios e valores capazes de levar a criança e o adolescente a viver de forma digna em sociedade.

Em relação ao inciso IV do artigo em questão, que proíbe a incidência reiterada nas faltas previstas no artigo 1.638, do Código Civil de 2002. Assim, Gonçalves (2017,p. 488) explica que se trata de uma maneira de impedir que os pais, de forma abusada, repitam condutas que isoladamente não levariam à destituição do poder familiar, mas apenas a uma pena branda de suspensão.

Não deixa dúvidas o inciso $\mathrm{V}$ do artigo em questão, estabelece que o filho só pode ser entregue para adoção de forma regular de acordo com a legislação vigente. Aquele que entrega o filho fora dos moldes da lei comete ato ilícito podendo ser destituído do poder familiar.

A lei 13.715/18 cuidou em alterar o artigo 1.638 do Código Civil, incluindo o parágrafo único para ampliar as possibilidades da perda do poder familiar nos seguintes casos:

Parágrafo único. Perderá também por ato judicial o poder familiar aquele que: I - praticar contra outrem igualmente titular do mesmo poder familiar: a) homicídio, feminicídio ou lesão corporal de natureza grave ou seguida de morte, quando se tratar de crime doloso envolvendo violência 
doméstica e familiar ou menosprezo ou discriminação à condição de mulher:

b) estupro ou outro crime contra a dignidade sexual sujeito à pena de reclusão;

II - praticar contra filho, filha ou outro descendente:

a) homicídio, feminicídio ou lesão corporal de natureza grave ou seguida de morte, quando se tratar de crime doloso envolvendo violência doméstica e familiar ou menosprezo ou discriminação à condição de mulher;

b) estupro, estupro de vulnerável ou outro crime contra a dignidade sexual sujeito à pena de reclusão.

Percebe-se que a lei $13.715 / 18$ se ateve aos vários casos de violência doméstica e familiar presentes no atual cenário brasileiro, o que impacta significativamente no melhor interesse da criança e do adolescente. Importa ressaltar que a referida lei também alterou o artigo 92, inciso II do Código Penal prevendo a incapacidade para o exercício do poder familiar daquele que detém a tutela ou curatela quando praticar crime doloso contra a vida do titular com igual poder familiar, ou ainda quando o crime praticado for contra o filho ou outro descendente, ou mesmo contra aquele que é tutelado ou curatelado. Nesse mesmo sentido, a lei $13.715 / 18$ ainda altera o Estatuto da Criança e do Adolescente em seu artigo 23.

Identifica-se que o Estado sempre visa buscar o melhor interesse da criança ou do adolescente, utilizando-se de medidas de correção de maneira pedagógica para que o pai ou a mãe não chegue a reincidir em suas faltas ao ponto de sofrerem medidas mais gravosas, na tentativa de se preservar o convívio familiar considerando o melhor interesse da criança e do adolescente. Desta forma, caberá aos pais cuidar para que os direitos da criança e do adolescente sejam devidamente observados, exercendo de forma irreparável o poder familiar (TARTUCE, 2017).

Considerando o princípio da proteção da criança e do adolescente ou do melhor interesse da criança, é importante ressaltar que a não violação deste princípio proporcionará o respeito a outros princípios assegurados na Constituição Federal, bem como nas leis esparsas, consequentemente a não privação ou restrição dos pais, ao exercício do poder familiar imposta mediante intervenção do estado pelo poder jurisdicional, assegurando à criança ou adolescente, de forma prioritária, os direitos adquiridos com o advento do poder familiar através da Constituição de 1988. 


\title{
5 A destituição do poder familiar como garantia da proteção integral à criança e ao adolescente
}

A proteção da criança e adolescente é compreendida desde o nascimento até a maioridade. Conforme elucida Maria Berenice Dias (2016, p. 120):

\begin{abstract}
o poder familiar é um dever dos pais o qual deve ser exercido sempre no interesse dos filhos, o Estado como guardião, tem o dever de fiscalizar se o exercício esta sendo realizado de acordo como preconiza a legislação, caso reste demonstrada ocorrência de violação aos direitos relativos ao poder familiar o Estado deverá intervir tomando as medidas necessárias para dar atendimento ao melhor interesse da criança/adolescente.
\end{abstract}

O exercício do poder familiar é um compromisso assumido pelos pais perante a sociedade. Dessa maneira, o poder familiar está subordinado a determinadas regras e limites.Com isso, quando um dos pais ou ambos violam direitos que protegem a criança e o adolescente, a perda do poder familiar pode ser decretada em relação a ambos os pais ou a um destes (MADALENO, 2016).

Ao aplicar a destituição do poder familiar, os efeitos na vida da criança ou adolescente, bem como na vida dos pais, são considerados graves, pois os pais perdem a autoridade e prerrogativas que possuíam em relação ao filho, por conseguinte, o vínculo de convivência afetivo é extinto, o que se considerada grave.

Por ser medida drástica, a destituição do poder familiar somente poderá ser aplicada conforme determina o artigo 1.635, V, do Código Civil, que remete para o artigo 1.638 do Código Civil, já devidamente mencionado no presente trabalho.Com base na legislação, nota-se que quando se trata de castigos mais severos, imoderados, consubstanciados em agressões, brutalidades, estes não têm o condão de trazer nenhum beneficio para o filho, e sim, violar a dignidade e a integridade psicológica e física deste (RODRIGUES, 2017).

Diante do abandono familiar a destituição do poder familiar pode ser decretada. Abandono este que se configura quando os pais privam o filho da convivência familiar ou não zelam pela formação moral e nem supremas necessidades materiais destes.De acordo com Rodrigues (2017, p. 88) o referido abandono é aquele que traduz-se:

$\mathrm{Na}$ falta de cuidado e atenção, na incúria, ausência absoluta de carinho e amor. É o pai que tem desleixo para com a prole, que pouco se lhe importa 
a nutrição, faltando aos cuidados básicos e essenciais à própria sobrevivência, e mantendo o filho em estado de indigência.

Assim, entende-se que a criança ou o adolescente deve conviver com sua família em um ambiente saudável e harmonioso, visto que quando a criança ou o adolescente convive em ambientes conturbados, com uso desregrado de bebidas alcoólicas, prostituição, dentre outros atos reprováveis, são induzidos a praticarem tais atos, na medida em que passam a considerar essas condutas normais.

Assim, a destituição do poder familiar pode representar, em alguns casos, uma garantia de vida digna para a criança ou adolescente, conforme afirma Rodrigues (2017, p. 92):

A suspensão ou destituição do poder familiar constituem, assim, sanções aplicadas aos pais pela infração ao dever genérico de exercerem o poder parental de acordo com regras estabelecidas pelo legislador, e visam atender ao maior interesse do menor. A nosso ver, tais sanções têm menos um intuito punitivo aos pais do que o de preservar o interesse dos filhos, afastando-os da nociva influência daqueles.

Importante trazer a baila o seguinte julgado:

APELAÇÃO CÍVEL - ESTATUTO DA CRIANÇA E DO ADOLESCENTE AÇÃO DE DESTITUIÇÃO DO PODER FAMILIAR - MEDIDA EXCEPCIONAL - NEGLIGÊNCIA DOS PAIS - COMPROVADA ABANDONO DOS MENORES - CONJUNTO PROBATÓRIO QUE RESPALDA PLENAMENTE ESSA DECISÃO - AÇÃO DE APURAÇÃO DE SITUAÇÃO DE RISCO - DESCUMPRIMENTO DOS DEVERES PRÓPRIOS DO PODER FAMILIAR - PODER FAMILIAR DESTITUÍDO - ART. 1938, CC E ART. 19, ECA- MELHOR INTERESSE DOS MENORES - SENTENÇA MANTIDA - RECURSO DESPROVIDO. "(...) Demonstrado o estado de abandono, em que se encontravam as crianças, e que os pais biológicos, em virtude da falta de estrutura familiar, não tem condições de exercer o poder familiar com responsabilidade, sua destituição é imperativo legal." (TJPR - 11aㅡ Câmara Cível - Apelação Cível n.ำ582839-3 -Rel. Des. Augusto Lopes Cortes - Acórdão n. 13860 - DJ 11/08/2009)

Com base nos ensinamentos doutrinários e jurisprudenciais, entende-se que a destituição do poder familiar não pode ser considerada como uma punição aos pais, e sim, uma garantia inerente a proteção dos direitos da criança ou adolescente. Ademais, sobre a destituição do poder familiar, mesmo sendo considerada como uma medida grave, em muitos casos, esta é a única forma possível de efetivar a proteção da criança e do adolescente. 


\section{Considerações finais}

O melhor interesse da criança e do adolescente é um princípio e direito consagrado na Constituição Federal, estando ligado intimamente ao poder familiar.

O estudo em questão buscou analisar as hipóteses de suspensão e perda do poder familiar. Resta demonstrada a relevância do estudo se considerada a urgência do debate sobre o tema, diante do atual cenário social, prova disso foi a preocupação do legislador ao ampliar o rol de hipóteses de perda e suspensão do poder familiar recentemente, após o início do projeto deste estudo.

Desta forma, espera-se com o estudo em comento proporcionar à sociedade melhor esclarecimento sobre o assunto, afim de que crianças e adolescentes tenham seus direitos resguardados e que detentores do poder familiar reflitam sobre a importância do melhor interesse da criança e do adolescente no atual cenário onde o pátrio poder não merece mais prosperar.

Esse trabalho teve como objetivos principais o esclarecimento sobre 0 conceito de poder familiar, as consequências jurídicas do não exercício do mesmo e debater a importância do Princípio da Proteção da Criança e do Adolescente.

Mediante os estudos, tais objetivos foram atingidos, uma vez que é amplo o debate doutrinário sobre a questão, dada a sua relevância, tanto que recentemente a legislação ampliou o rol de possibilidades da perda do poder familiar, se atentando para a preservação do princípio da proteção da criança e do adolescente.

Sendo o poder familiar a autoridade que os pais tem diante dos filhos sobre os seus bens, direitos e obrigações, ainda que temporariamente, vez que se trata de filhos menores, devem os referidos pais buscarem a preservação do melhor interesse da criança e do adolescente, conforme consagrado na Constituição Federal de 88 em seu artigo 227 para que haja harmonia da família e dos filhos.

Desta forma, os pais precisam estar atentos aos atributos a eles confiados, para que o exercício do poder familiar seja mantido, pois a violação ao princípio do melhor interesse da criança e do adolescente será capaz não apenas de suspender tais atributos, bem como de fazer com que esses sejam aniquilados, como forma de proteção ao menor, em consequência do prejuízo que lhes foi causado.

Assim, a destituição do poder familiar, apesar de ser considerada como uma medida grave, tem o condão de garantir que os direitos inerentes a criança e ao 
adolescente venham ser respeitados, por conseguinte, estes possam a conviver em um ambiente mais harmonioso e saudável.

\section{Referências}

BRASIL. Constituição da República Federativa do Brasil de 1988. Brasília, 1988. . Lei 10. 406 de 10 de Janeiro de 2002. Código Civil Institui o Código Civil. Brasília, DF, 2018.

. Lei $\mathrm{n}$ - 13.715, de 24 de setembro de 2018. Altera o Decreto-Lei $\mathrm{n}^{\circ} \mathbf{2 . 8 4 8}$, de 7 de dezembro de 1940 (Código Penal), a Lei no 8.069, de 13 de julho de 1990 (Estatuto da Criança e do Adolescente), e a Lei no 10.406, de 10 de janeiro de 2002 (Código Civil), para dispor sobre hipóteses de perda do poder familiar pelo autor de determinados crimes contra outrem igualmente titular do mesmo poder familiar ou contra filho, filha ou outro descendente. Disponível em<http://www.planalto.gov.br/ccivil_03/_Ato2015-2018/2018/Lei/L13715.htm>. Acesso em: 28 maio 2019.

Lei $n^{\circ}$ 3.071, de $1^{\circ}$ de janeiro de 1916. Código Civil dos Estados Unidos do Brasil (Revogada). Disponível em:

<http://www.planalto.gov.br/ccivil_03/leis/l3071.htm>. Acesso em: 28 maio 2019.

Lei no 8069 de 13 de julho de 1990. Estatuto da Criança e do

Adolescente.Dispõe sobre o Estatuto da Criança e do Adolescente e dá outras providências. Brasília, DF, 2012.

. Tribunal de Justiça do Paraná - 11a Câmara Cível - Apelação Cível n.o 582839-3 -Rel. Des. Augusto Lopes Cortes - Acórdão n. 13860 - DJ 11/08/2009. Disponível em: <https://www.jusbrasil.com.br/diarios/51047522/djpr-20-02-2013-pg990?ref=next_button>. Acesso em: 30 maio 2019.

DIAS, Maria Berenice. Manual de direito das famílias. 11a. ed. São Paulo: Ed. Revista dos Tribunais Ltda, 2016.

GONÇALVES, Carlos Roberto. Direito Civil Brasileiro: Direito de Família. 14ª ed. São Paulo. Ed. Saraiva, 2017.

LÔBO, Paulo. Direito Civil - Famílias. 4ª̣ ed. São Paulo. Ed. Saraiva, 2011.

MADALENO, Rolf. Direito de família. 7ª̣. ed. Rio de Janeiro: Ed. Forense, 2016.

PEREIRA, Caio Mário da Silva. Instituições de Direito Civil: Direito de Família. Vol. V. 25 $5^{\mathrm{a}}$ ed. Rio de Janeiro. Ed. Forense, 2017.

RODRIGUES, Silvio. Direito civil: direito de família. Vol. 6. São Paulo: Saraiva, 2017.

TARTUCE, Flávio. Direito Civil: Direito de Família.12 $12^{\underline{a}}$ ed. Rio de Janeiro: Ed. Forense, 2017. 